\title{
Encapsulation and 3D culture of human adipose-derived stem cells in an in-situ crosslinked hybrid hydrogel composed of PEG-based hyperbranched copolymer and hyaluronic acid
}

\author{
Waqar Hassan ${ }^{\dagger}$, Yixiao Dong ${ }^{\dagger}$ and Wenxin Wang ${ }^{*}$
}

\begin{abstract}
Introduction: Cell therapy using adipose-derived stem cells has been reported to improve chronic wounds via differentiation and paracrine effects. One such strategy is to deliver stem cells in hydrogels, which are studied increasingly as cell delivery vehicles for therapeutic healing and inducing tissue regeneration. This study aimed to determine the behaviour of encapsulated adipose-derived stem cells and identify the secretion profile of suitable growth factors for wound healing in a newly developed thermoresponsive PEG-hyaluronic acid (HA) hybrid hydrogel to provide a novel living dressing system.

Methods: In this study, human adipose-derived stem cells (hADSCs) were encapsulated in situ in a water-soluble, thermoresponsive hyperbranched PEG-based copolymer (PEGMEMA-MEO $2 M A-P E G D A$ ) with multiple acrylate functional groups in combination with thiolated $\mathrm{HA}$, which was developed via deactivated enhanced atom transfer radical polymerisation of poly(ethylene glycol) methyl ether methacrylate (PEGMEMA, Mn = 475), 2-(2-methoxyethoxy) ethyl methacrylate $\left(\mathrm{MEO}_{2} \mathrm{MA}\right)$ and poly(ethylene glycol) diacrylate PEGDA $(\mathrm{Mn}=258)$. hADSCs embedded in the PEGMEMA-MEO 2 MA-PEGDA and HA hybrid hydrogel system (P-SH-HA) were monitored and analysed for their cell viability, cell proliferation and secretion of growth factors (vascular endothelial growth factor, transforming growth factor beta and placental-derived growth factor) and cytokines (IFNy, IL-2 and IL-10) under three-dimensional culture conditions via the ATP activity assay, alamarBlue ${ }^{\circledR}$ assay, LIVE/DEAD ${ }^{\circledR}$ assay and multiplex ELISA, respectively.

Results: hADSCs were successfully encapsulated in situ with high cell viability for up to 7 days in hydrogels. Although cellular proliferation was inhibited, cellular secretion of growth factors such as vascular endothelial growth factor and placental-derived growth factor production increased over 7 days, whereas IL-2 and IFNY release were unaffected.

Conclusion: This study indicates that hADSCs can be maintained in a P-SH-HA hydrogel, and secrete pro-angiogenic growth factors with low cytotoxicity. With the potential to add more functionality for further structural modifications, this stem cell hydrogel system can be an ideal living dressing system for wound healing applications.
\end{abstract}

Keywords: Human adipose-derived stem cells, Hyaluronic acid, PEG hyperbranched polymers, Hydrogels, Wound healing

\footnotetext{
* Correspondence: wenxin.wang@nuigalway.ie

${ }^{\dagger}$ Equal contributors

Network of Excellence for Functional Biomaterials, National University of

Ireland, Galway, IDA Business Park, Dangan, Galway, Ireland
} 


\section{Introduction}

Chronic wound healing has remained difficult despite the advances in tissue engineering such as bioengineered skin substitutes [1]. At least 50\% of chronic wounds remain resistant to advanced or standard treatments such as growth factor delivery or bioengineered skin substitutes [2]. In recent years, stem cell-based therapies have emerged as therapeutic alternatives in the regeneration and repair of damaged organs and tissues for various diseases [3]. Recent studies in delayed wound healing animal models using stem cells have been encouraging in treating of chronic wounds [4,5]. Among the many factors contributing to impaired wound healing, the main factors are the reduction of cytokines and reduced neovascularisation [6,7]. Bone marrow-derived stem cells have been shown to modulate the immune response and provide the building blocks for the regeneration of wounds in recent studies $[8,9]$. Furthermore, adipose-derived stem cells have shown multipotency and secrete many growth factors such as insulin-like growth factor, hepatocyte growth factor, transforming growth factor beta 1 (TGF- $\beta 1$ ) and vascular endothelial growth factor (VEGF) that are essential in wound healing and have been shown to heal chronic wounds in preclinical wound healing models [10-13]. In a recent study, human adipose-derived stem cells (hADSCs) embedded in a collagen hydrogel secreted increased levels of growth factors to enhance wound healing [14].

The main strategy to deliver stem cells or growth factors to chronic wounds involves direct injection to the injury site. However, this method leads to poor engraftment and poor efficacy due to proteolytic degradation within the first few hours post injection, thus preventing the beneficial effects of these expensive biological agents $[15,16]$. These problems can be overcome with the use of a delivery scaffold of natural or synthetic origin. Hydrogel scaffolds have recently been extensively studied because their hydrophilic and injectable properties make them a suitable delivery system for drugs and stem cell therapy [17-21]. Hydrogels can encapsulate stem cells and maintain good viability while keeping their phenotype, which can provide a three-dimensional (3D) microenvironment for stem cells to closely mimic the in vivo conditions leading to stimulation of cellular proliferation, differentiation and regeneration via physical or chemical cues [22-24]. However, most of these hydrogel systems are developed via UV crosslinking or require multistep chemically modified reactions and purification methods, which causes safety concerns and increased cost as well as requiring complex preparation methods $[25,26]$.

A PEG-based thermoresponsive hyperbranched copolymer of poly(ethylene glycol) methyl ether methacrylate-co2-(2-methoxyethoxy) ethyl methacrylate-co-poly(ethylene glycol) diacrylate (PEGMEMA $475-\mathrm{MEO}_{2} \mathrm{MA}-\mathrm{PEGDA}_{258}$ ) was developed recently using a one-pot and one-step deactivated enhanced atom transfer radical polymerisation method in our group [27]. This copolymer exhibited a lower critical solution temperature that was close to body temperature. Once the polymer solution was applied at body temperature, a thermal gelation rapidly occurred. In addition, with high content of vinyl functional groups, this polymer further crosslinks chemically with thiolated hyaluronan (HA-SH) in minutes via a Michaeltype thiolene reaction, which increases the mechanical properties of the hydrogel. This thermoresponsive hydrogel system allows in situ encapsulation of stem cells in a very short period of time, which can be used to deliver cells and growth factors. The secretion of growth factors from embedded cells could help induce the healing process in chronic wounds (Figure 1C).

The purpose of this study is to analyse this system for soft-tissue engineering by successful encapsulation of hADSCs in situ. The effects of the PEGMEMA$\mathrm{MEO}_{2} \mathrm{MA}-\mathrm{PEGDA}$ and HA hybrid (P-SH-HA) hydrogel on cellular toxicity, proliferation and secretion of proinflammatory/anti-inflammatory and angiogenic growth factors were examined. Herein, we describe the preliminary characterisation of P-SH-HA synthetic extracellular matrix hydrogels for use in cell culture in vitro and with potential application in vivo.

\section{Methods \\ Materials}

The chemicals PEGMEMA ( $\mathrm{Mn}=475 \mathrm{~g} / \mathrm{mol}), \mathrm{MEO}_{2} \mathrm{MA}$, and PEGDA $(\mathrm{Mn}=258 \mathrm{~g} / \mathrm{mol})$ were purchased from Sigma-Aldrich (Wicklow, Ireland). HA-SH (HyStem ${ }^{\mathrm{TM}}$, Glycosan) was purchased from BioTime Inc. (Alameda, CA, USA). All chemicals were of analytical grade.

\section{PEGMEMA-MEO 2 MA-PEGDA polymer synthesis and characterisation}

The PEGMEMA-MEO ${ }_{2} \mathrm{MA}-\mathrm{PEGDA}$ copolymer was synthesised by the copolymerising of PEGMEMA, $\mathrm{MEO}_{2} \mathrm{MA}$ and PEGDA via an in situ deactivation-enhanced atom transfer radical polymerisation approach as previously described [28]. Briefly, PEGMEMA (7.4 g, 0.015 moles), $\mathrm{MEO}_{2} \mathrm{MA}$ (12.8 g, 0.068 moles), PEGDA (5.4 g, 0.021 moles), the initiator ethyl 2-bromoisobutyrate ( $155 \mu \mathrm{l}, 0.001$ moles), copper(II) chloride (0.032 g, 0.0002 moles), bis(2dimethylaminoethyl)methylamine (64 $\mu \mathrm{l}, 0.0002$ moles) were added to a two-neck flask in $25 \mathrm{ml}$ solvent butanone. The mixture was stirred for complete dissolution followed by purging with argon for 30 minutes to remove dissolved oxygen. L-Ascorbic acid $(0.011 \mathrm{~g})$ was added to the polymerisation solution under argon conditions and the mixture was heated in an oil bath to $50^{\circ} \mathrm{C}$ and stirred for 6 hours.

The polymerisation was stopped by opening the flask and exposing the catalyst to air. After the polymerisation, 

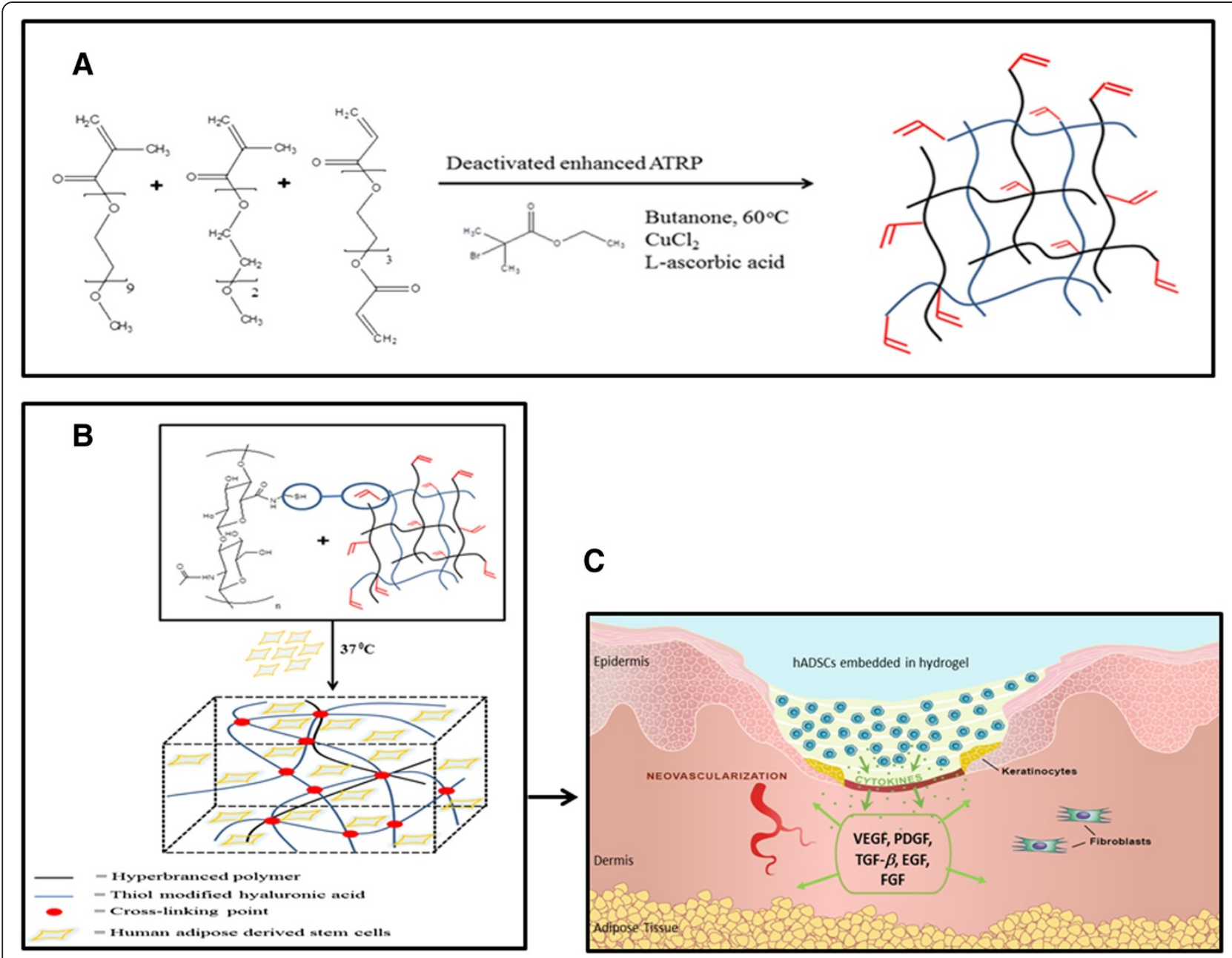

Figure 1 Schematic illustration of PEGMEMA $475-\mathrm{MEO}_{2} \mathrm{MA}-\mathrm{PEGDA}_{258}$ copolymer synthesis and cross-linking with thiol-modified hyaluronic acid. (A) Synthesis route via deactivation-enhanced atom transfer radical polymerisation (ATRP) at $60^{\circ} \mathrm{C}$. (B) Cross-linking of PEGMEMA-MEO 2 MA-PEGDA and HA hybrid (P-SH-HA) polymer with thiol-modified hyaluronic acid via Michael-type addition reaction showing encapsulation of human adipose-derived stem cells (hADSCS) in the P-SH-HA hydrogel at $37^{\circ} \mathrm{C}$. (C) Cartoon picture: application of P-SH-HA

hydrogel on a skin wound. The hADSCs are embedded in situ with P-SH-HA hydrogel and applied on the wound, which secrete growth factors to accelerate wound healing. EGF, epidermal growth factor; FGF, fibroblast growth factor; PDGF, platelet-derived growth factor; TGF- $\beta$,

transforming growth factor beta; VEGF, vascular endothelial growth factor.

the solution was diluted with (1:1) acetone and precipitated into a large excess of diethyl ether and hexane (1:1.2) to remove solvent and monomers. The precipitated mixture of the polymer was dissolved in deionised water and purified by dialysis (spectrum dialysis membrane, molecular weight cutoff 6,000 to 8,000 ) for 72 hours in a dark environment at $4^{\circ} \mathrm{C}$ against fresh deionised water, while the water was changed regularly. The pure polymer samples were obtained after freeze drying. The molecular weight and molecular weight distributions were determined for PEGMEMA-MEO $\mathrm{M}_{2} \mathrm{MA}-\mathrm{PEGDA}$ using gel permeation chromatography (Polymer Laboratories) (Amherst, MA, USA) with an (Refractive Index) detector using dimethylformamide as an eluent. The columns $(30 \mathrm{~cm}$ PLgel Mixed-C, two in series) were calibrated with poly (methyl methacrylate) standards. All calibrations and analysis were performed at $60^{\circ} \mathrm{C}$ and a flow rate of $1 \mathrm{ml} /$ minute. ${ }^{1} \mathrm{H}$ NMR was carried out for PEGMEMA-MEO ${ }_{2}$ MA-PEGDA on a $300 \mathrm{MHz}$ Bruker NMR with MestReC processing software. The chemical shifts were referenced to the lock chloroform $\left(\mathrm{CDCl}_{3}\right)$ for PEGMEMA-MEO ${ }_{2} \mathrm{MA}-\mathrm{PEGDA}$ (Sigma, Wicklow, Ireland).

\section{Hydrogel preparation}

Commercially available HA-SH (Glycosan-HyStem ${ }^{\mathrm{TM}}$; BioTime Inc.) was used for making hydrogels,. The hydrogel was prepared by reacting the vinyl groups on the hyperbranched copolymer with free thiol contents of HA$\mathrm{SH}$ at physiological condition via Michael-type addition. For this purpose, HA-SH (1\% w/v) and PEGMEMA- 
$\mathrm{MEO}_{2} \mathrm{MA}-\mathrm{PEGDA}(10 \% \mathrm{wt})$ were prepared in PBS $(\mathrm{pH}$ 7.4) in separate glass vials. The two solutions were combined in a volume ratio of 1:1 and gently mixed for 30 seconds. The solution was than incubated at $37^{\circ} \mathrm{C}$ to obtain gels for further analysis.

\section{Cell culture}

STEMPRO $^{\circledR}$ hADSCs (Invitrogen) (Life Technologies, Dublin, Ireland) isolated from human adipose tissue collected during liposuction procedures were obtained at passage 1. The cells were grown and passaged using MesenPRO $\mathrm{RS}^{\mathrm{TM}}$ Medium (includes basal medium and growth supplement; Invitrogen) during all of the studies and used between passages 2 and 4 . These cells have been shown to express a cell-surface protein profile that is positive for CD29, CD44, CD73, CD90, CD105, and CD166 (>95\%), and is negative for CD14, CD31, CD45, and $\operatorname{Lin} 1(<2 \%)$.

\section{Two-dimensional and three-dimensional cell culture}

For two-dimensional (2D) culture, hADSCs were seeded on a 96-well plate (2D) at a final concentration of $0.5 \times 10^{6}$ cells $/ \mathrm{ml}$. Similarly, for 3D culture the cell suspension was mixed with PEGMEMA-MEO ${ }_{2}$ MA-PEGDA and HA-SH at a final concentration of $0.5 \times 10^{6}$ cells $/ \mathrm{ml}$. After gelation, the cell laden gel constructs were transferred to a 48-well plate and $0.5 \mathrm{ml}$ MesenPRO $\mathrm{RS}^{\mathrm{TM}}$ media were added supplemented with $2 \%$ growth supplement (Invitrogen). The media was changed every second day. Tissue culture plastic (TCP) seeded cells were used as experimental controls in all experiments.

\section{Cell viability}

The alamarBlue ${ }^{\circledR}$ (Invitrogen) assay was performed to evaluate the metabolic activity of hADSCs in the 3D cell culture system. hADSCs were encapsulated in 3D hydrogels as described above. At each time point, cells were washed three times with $\mathrm{PBS}$ at $37^{\circ} \mathrm{C}$, following which $10 \%$ alamarBlue ${ }^{\circledR}$ in MesenPRO $\mathrm{RS}^{\mathrm{TM}}$ cell culture media was added to the wells containing hydrogel constructs to assess the cell metabolic activity after 1, 3, 5 and 7 days. Viability of encapsulated cells was also measured via intracellular ATP activity using Celltiter-Glo ${ }^{\circledR}$ reagent (Promega) (Madison, WI, USA) at days 2, 5 and 7. Media from cell-laden hydrogels were removed and replaced with $200 \mu \mathrm{l}$ of $50 \%$ Celltiter-Glo ${ }^{\circledR}$ reagent in MesenPRO $\mathrm{RS}^{\mathrm{TM}}$ media. Following incubation on a shaker for 45 minutes at room temperature, $150 \mu \mathrm{l}$ of the solutions were transferred into a 96-well white plate for luminescence quantification using a microplate reader. The LIVE/DEAD ${ }^{\circledR}$ assay (Molecular Probes) (Life Technologies, Dublin, Ireland) was also used to visualise the distribution of living and dead cells in the hydrogel at different time points for the 3D culture system.
Fluorescence images were taken using an Olympus Fluoview Confocal Microscope.

\section{Cell proliferation assay}

Cell proliferation was determined using PicoGreen ${ }^{\circledR}$ fluorescent DNA quantification (Molecular Probes) kit at days 2 and 7 for both 3D and 2D culture as described by the manufacturer. DNA from cell-laden hydrogels was recovered by first mechanically digesting hydrogels and then enzymatically in proteinase $K$ overnight at $56^{\circ} \mathrm{C}$. Briefly, $100 \mu \mathrm{l}$ DNA samples were incubated with $100 \mu$ l diluted (1:200) PicoGreen ${ }^{\circledR}$ reagent in $1 \times$ TE buffer in a 96-well opaque, flat-bottomed assay plate. The fluorescence was read at excitation $485 \mathrm{~nm}$ and emission $525 \mathrm{~nm}$ and was compared with a DNA standard curve provided with the kit.

\section{Determination of growth factor secretion}

After each predetermined time point (days 1, 3, 5 and 7), conditioned media from both $2 \mathrm{D}$ and $3 \mathrm{D}$ culture systems was collected and stored at $-80^{\circ} \mathrm{C}$ for later analysis of the secreted factors using a multiplex ELISA system. The media was not changed in these samples until 7 days. The cell-laden hydrogels (3D) and cells on TCP (2D) were also harvested and stored at $-80^{\circ} \mathrm{C}$ until further analysis. The conditioned media of hADSCs were analysed (days 1, 3, 5 and 7) for both the angiogenic growth factors VEGF, placental-derived growth factor (PIGF), TGF- $\beta$ and the proinflammatory/anti-inflammatory cytokines IFN $\gamma$, IL-2 and IL-10 by the Mesoscale development system with multiplex ELISA kits (MSD TH1/TH2 7-plex, MSD Human Growth factor 1 4-Plex) (Meso Scale Discovery, Gaithersburg, MD, USA) as described by the manufacturer.

\section{Statistical analysis}

All data are expressed as mean \pm standard deviation of triplicate samples. Comparisons between multiple groups were performed using one-way ANOVA. All analyses were performed with GraphPad Prism 5 (CA, USA). Differences between two datasets were considered significant when $P<0.05$.

\section{Results and discussion}

3D culture systems have frequently been used to mimic in vivo conditions. These systems allow for the control of cellular behaviour by providing control over properties of material substrates and microenvironments using natural or synthetic materials. This control allows creation of a stem cell niche to maintain or control the stemness of cells. Many synthetic and biological 3D systems such as collagen, hyaluronic acid, PEG-based synthetic extracellular matrix (QGEL ${ }^{\mathrm{TM}}$ ) (Lausanne, Switzerland) and chitosan have been reported recently [24]. However, most of these systems are synthesised via chemical modifications, 
which require multistep reactions and purification methods leading to increased production costs as well as giving rise to complex preparation methods. To overcome these problems, a hyperbranched PEG-based copolymer was therefore recently synthesised using a one-pot and one-step synthesis method (Figure 1A). This synthesis creates a hydrogel with thermoresponsive properties and desired end functionality to provide an in situ crosslinking system that can crosslink with HA-SH via Michael-type addition (Figure 1B). This hydrogel system allows encapsulation of stem cells in situ, which could potentially be used as a system to form a dressing upon application for wound repairs (Figure 1C). Understanding stem cell behaviour and analysing the ability for cells to secrete growth factors is therefore essential. In this paper, PEG-based thermoresponsive copolymer cross-linked with HA-SH was studied for hADSC viability, proliferation and secretion of pro-angiogenic growth factors and inflammatory cytokines under $3 \mathrm{D}$ culture condition. Cells seeded on TCP (2D) were used throughout the experiments to provide experimental control for the secretion of growth factors, proliferation of cells and viability.

\section{PEGMEMA-MEO 2 MA-PEGDA polymer synthesis and characterisation}

Synthesis and characterisation of the PEGMEMA$\mathrm{MEO}_{2} \mathrm{MA}-\mathrm{PEGDA}$ copolymer was carried out as previously reported [28]. The reaction for the polymer was stopped when the desired molecular weight $(70 \mathrm{kDa})$ was reached. The hyperbranched structure of the polymer was confirmed by ${ }^{1} \mathrm{H}-\mathrm{NMR}$ and peaks at chemical shift of 6.4 to $5.8 \mathrm{ppm}$ proved the presence of a vinyl functional group as described previously [28].

\section{Cell morphology in P-SH-HA hydrogel}

Cellular morphology is an important phenomenon that is correlated with important biochemical functions involved in new tissue formation such as proliferation and migration of cells. It is known that cells encapsulated in PEG-based hydrogels without any attachment sites adopt rounded morphology unless some extracellular matrix materials are present [29]. The cell morphology for hADSCs was therefore evaluated within the hydrogels (3D) after encapsulation. It was noted the hADSCs were stretched with spindle-like shape on 2D culture as expected. In contrast, the cells in hydrogels lost this morphology and showed more rounded, isolated distribution throughout the gel (Figure 2). The spreading, migration and attachment of cells in the 3D microenvironment is dependent on many different factors; mainly substrate density, stiffness, elastic modulus, degradation and adhesion within the microenvironment of the hydrogels. Cells seeded on HA hydrogels have been shown to spread via CD44 and its co-receptor RHAMM [30]. In other studies, however, encapsulated cells in HA hydrogels do not spread but maintain good viability [30,31]. Our results agree with the latter studies, suggesting that hADSCs can remain viable in P-SH-HA copolymer without spreading. This could be due to the lack of presentation of attachment sites and receptors because of the highly cross-linked network.

\section{Cellular viability in P-SH-HA hydrogel}

To evaluate the biocompatibility of the hydrogels with hADSCs, quantitative cellular metabolic activity and viability were assessed using the alamarBlue ${ }^{\circledR}$ assay and the ATP assay, respectively. Qualitative analysis was carried out via the LIVE/DEAD ${ }^{\circledR}$ assay. hADSCs were encapsulated in hydrogel scaffold at a final concentration of $0.5 \times 10^{6}$ cells $/ \mathrm{ml}$ for up to 7 days. Unseeded hydrogels alone were used as negative control and tissue culture plastic (2D) seeded hADSCs were used as positive experimental controls. The alamarBlue ${ }^{\circledR}$ assay was utilised to test the viability of encapsulated cells at each time point. It was noted that after day 7 (49\%), cellular activity remained stable in comparison with day 1 (47\%). This indicates that there was no cytotoxic effect on cell metabolic activity from the hydrogel system (Figure 3A). Similar results were shown by ATP intracellular activity, which remained above $82 \%$ for 7 days (Figure 3B).

The LIVE/DEAD ${ }^{\circledR}$ assay (Molecular Probes) was employed to visualise the distribution of living and dead cells after 2, 5 and 7 days in the 3D cell culture system (Figure 4). Calcein AM fluoresces green upon the reaction of intracellular esterase and stains live cells; ethidium homodimer-1, which binds to the DNA of dead membrane compromised cells, stains dead cells (red). Few dead cells appeared after 5 days; however, the number of live cells was obviously much higher even after 7 days. We assumed that the hydrogel density that was increased further by thermal gelation in addition to chemical gelation and the nondegradable property of the hydrogel have limited the living space for the encapsulated cells and that the exchange of nutrients may not have been efficient and could have caused a slight drop in cell viability after 7 days. Overall, one can conclude that this nontoxic in situ gelling system can provide a suitable microenvironment in which hADSCs remain viable for up to 7 days.

\section{Cellular proliferation in P-SH-HA hydrogel}

The cell-encapsulated hydrogel samples prepared as mentioned above were digested mechanically and enzymatically with proteinase $\mathrm{K}$ prior to analysis. The DNA content was recovered and analysed with PicoGreen ${ }^{\circledR}$ assay after day 2 and day 7. The concentration of DNA from encapsulated cells was maintained at similar levels across both time periods; that is, $82.12 \pm 19.20 \mathrm{ng} / \mathrm{ml}$ at day 2 and $90.15 \pm 3.80 \mathrm{ng} / \mathrm{ml}$ at day 7 (Figure 5). The proliferation rate from $3 \mathrm{D}$ seeded cells was significantly 

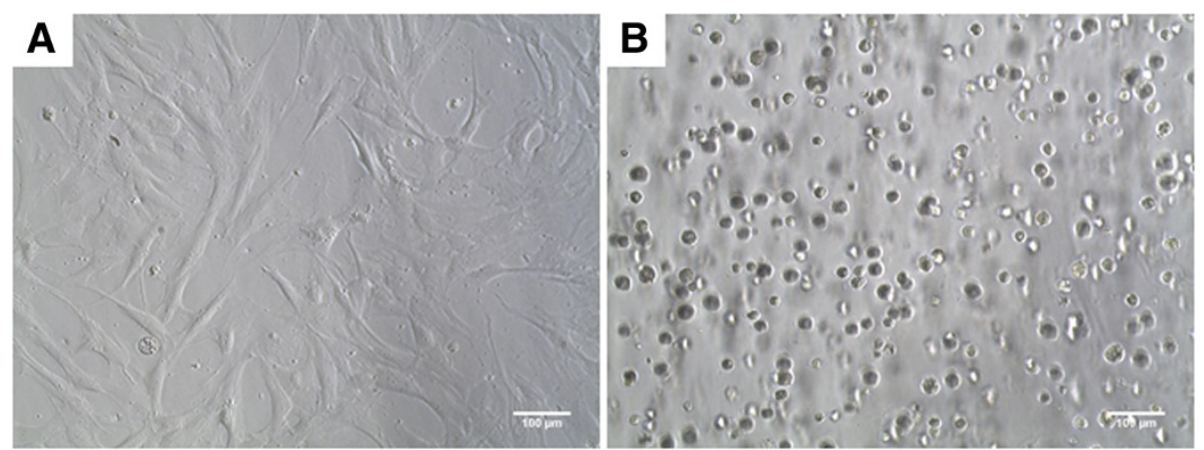

Figure 2 Phase images of tissue culture plastic and hydrogel encapsulated human adipose-derived stem cells. Phase image of tissue culture plastic (TCP; two-dimensional) and hydrogel (three-dimensional) encapsulated human adipose-derived stem cells (hADSCs) exhibiting (A) fibroblastic-like morphology and (B) rounded morphology after 2 days of seeding. hADSCs were seeded at a final concentration of $0.5 \times 10^{6}$ cells $/ \mathrm{ml}$ in a 96-well plate.

lower than that for $2 \mathrm{D}$ seeded cells. This phenomenon has been reported elsewhere and might be attributable to the cellular microenvironment [32]. These results indicate that the hADSCs did not proliferate in hydrogel even after 7 days. For spreading and migration of cell in a 3D structure, they need to be able to degrade the polymeric structure or extracellular matrix. HA is a degradable molecule; however, when cross-linked with a PEG-based polymer it can become difficult for cells to degrade. Cells secreting hyaluronidase can degrade the P-SH-HA
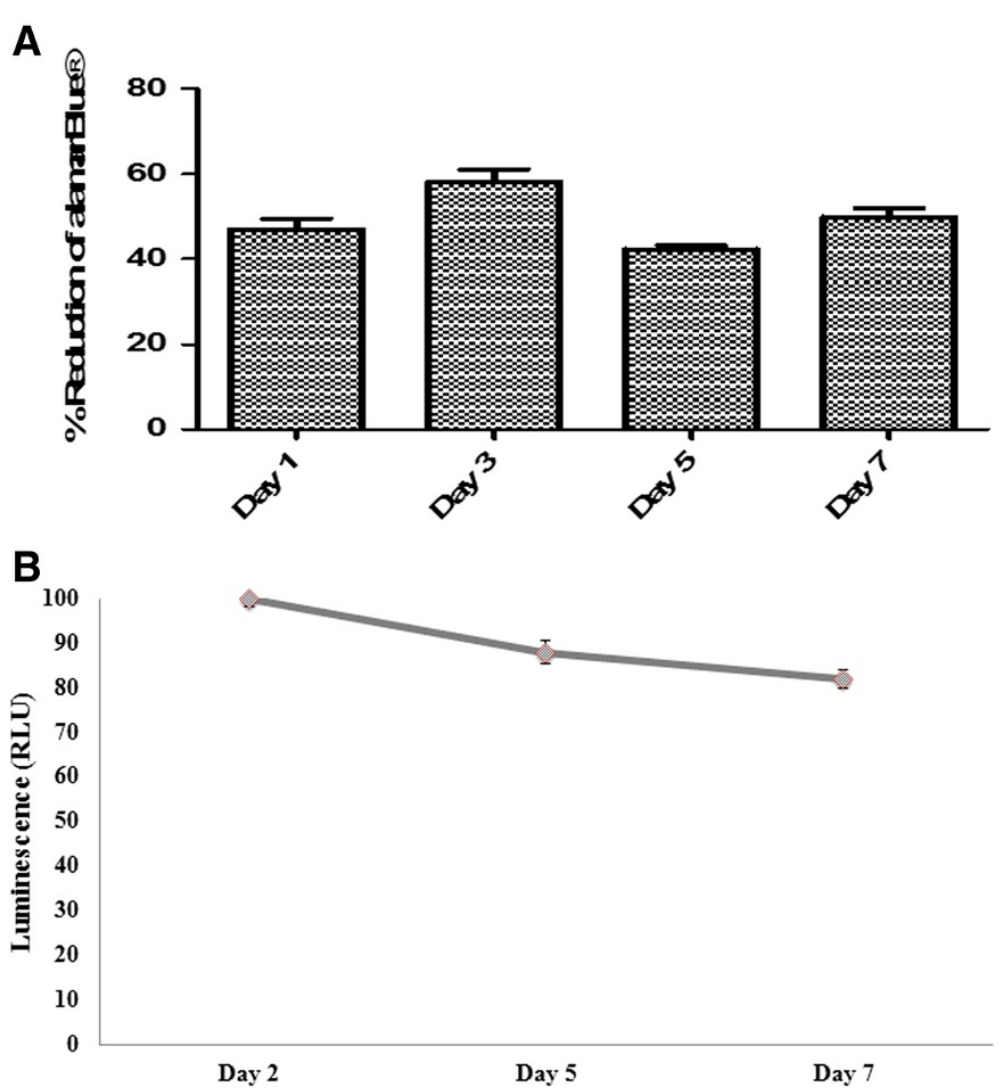

Figure 3 Cellular metabolic activity and viability of encapsulated human adipose-derived stem cells. (A) The alamarBlue ${ }^{\circledR}$ metabolic assay (Invitrogen ) (Life Technologies, Dublin, Ireland) for encapsulated human adipose-derived stem cells (hADSCs) in PEGMEMA-MEO 2 MA-PEGDA and HA hybrid hydrogels at days 2, 5 and 7 (mean \pm standard deviation, $n=3$ ). (B) Intracellular activity of ATP of hADSCs was measured at the indicated time after encapsulation and was used to represent cell metabolic activity and viability (mean \pm standard deviation, $n=3$ ). RLU, relative luminescence units. 


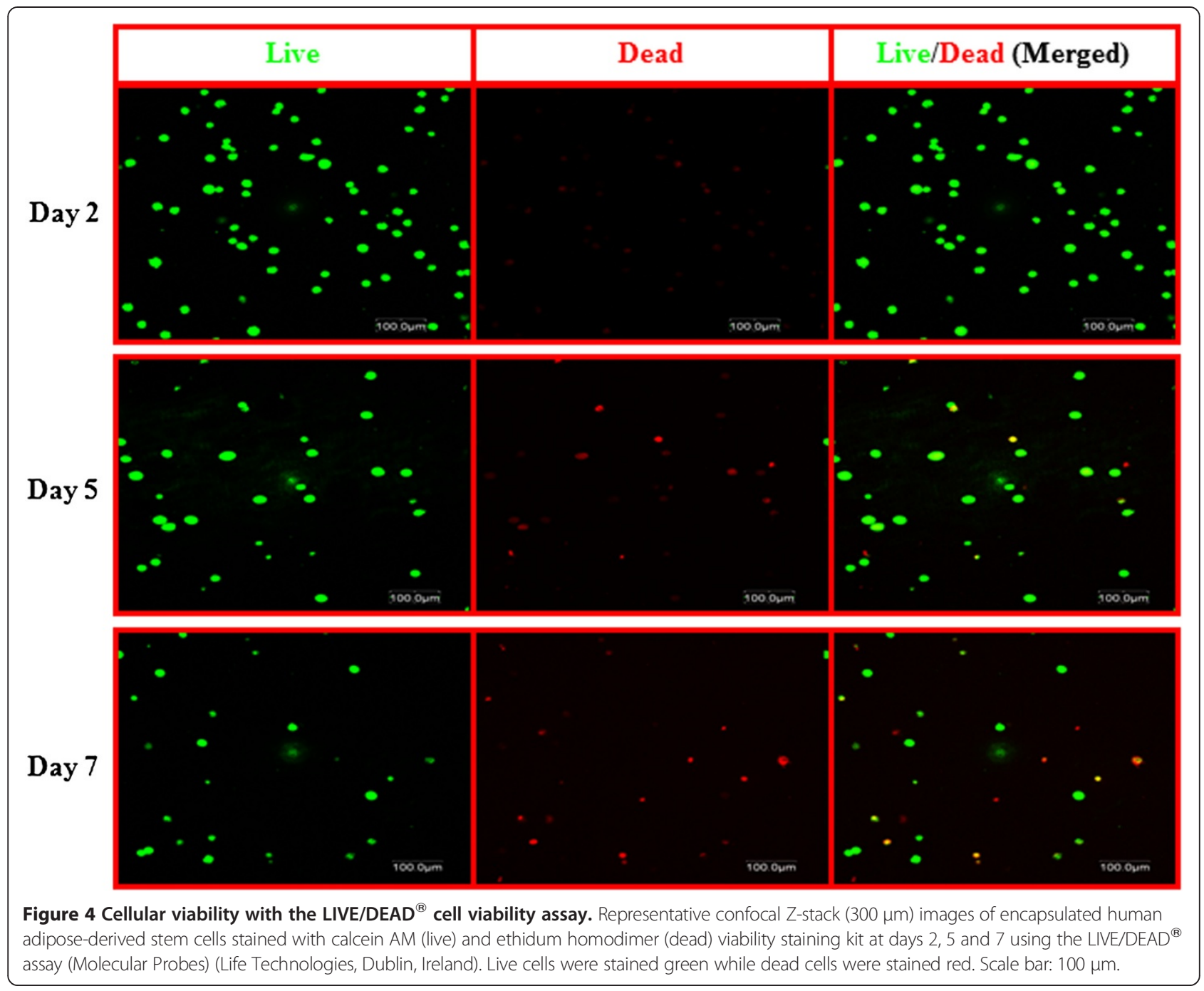

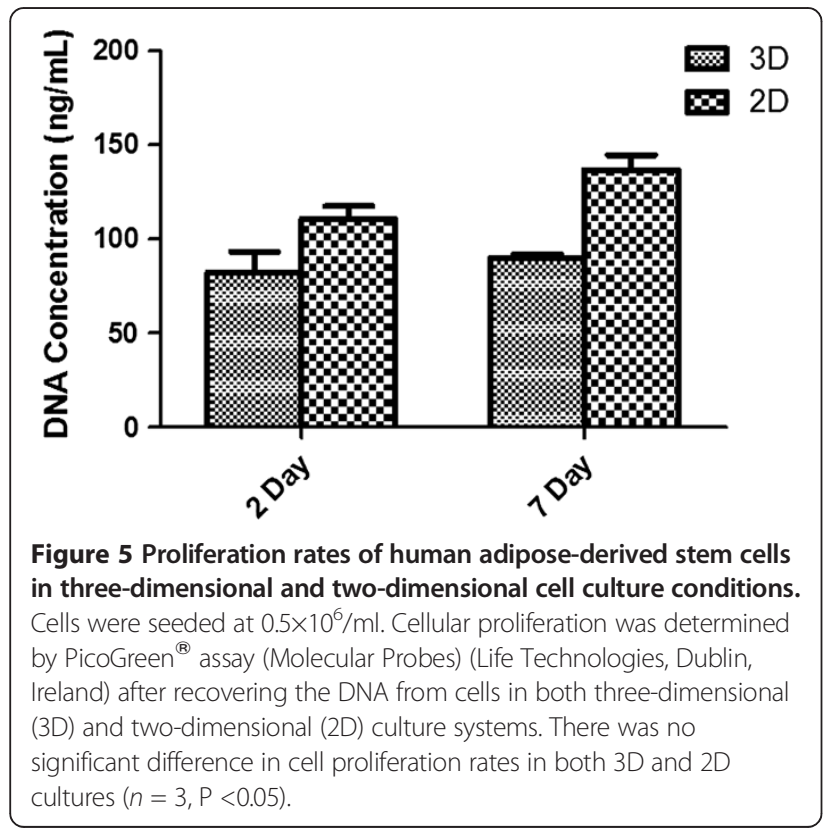

scaffold partially but this degradation is not sufficient to create enough space for cells to move around and proliferate. Our results here agree with other reports suggesting that nondegradable HA hydrogels suppress proliferation of mammalian cells, but can maintain viability [32].

\section{Secretion analysis of angiogenic and inflammatory} cytokines

Growth factors and cytokines are important mediators that allow cell-cell communication between other cell types that have been shown to play important roles in normal physiological and pathological processes. For example, proinflammatory cytokines are mainly involved in early stages of wound healing via inflammatory cells and if not properly regulated can lead to abnormal wound healing. In response to different materials, cells can react and produce inflammatory cytokines. Analysing the cellular response to newly developed biomaterials is therefore necessary. For this purpose we selected IL-2 and 
IFN $\gamma$, which are proinflammatory cytokines and may lead to detrimental effects if not controlled properly.

From our results, the inflammatory cytokines analysed were interestingly reduced from $28.38 \pm 5.14 \mathrm{ng} / \mathrm{ml}$ at day 1 to $7.38 \pm 1.60$ at day $7 \mathrm{ng} / \mathrm{ml}$ for IFN $\gamma$ (Figure 6) and from $2.73 \pm 1.52 \mathrm{ng} / \mathrm{ml}$ at day 1 to $0.82 \pm 0.21$ $\mathrm{ng} / \mathrm{ml}$ at day 7 for IL-2 in the 3D microenvironment (Figure 6). Media from cells seeded on TCP were used to analyse the $2 \mathrm{D}$ and $3 \mathrm{D}$ conditions for all time-points. TCP seeded cells acted as positive controls to measure cytokines and growth factors for ELISA because hADSCs have shown to secrete a detectable amount of growth factor in 2D conditions. There was no significant difference in secretion of IFNY and IL-2 at any time point for TCP seeded cells. This indicated that the P-SH-HA hydrogel scaffold did not induce an inflammatory response and that the hydrogel is a suitable scaffold system for cell encapsulation. For IL-10, an anti-inflammatory cytokine that has been reported to be beneficial in dampening down the immune response and can aid in impaired wound healing, no significant difference was observed in both 3D and 2D culture. However, it was noted that levels of IL-10 started to drop after day 3 in 2D culture but remained at stable levels in 3D culture over 7 days $(4.60 \pm 1.07 \mathrm{ng} / \mathrm{ml})$, which may provide an indication that presence of HA in the hydrogel scaffold can modulate an anti-inflammatory response from the encapsulated cells. The secretion analysis suggests that the hydrogel scaffold developed here does not induce an inflammatory reaction from the encapsulated cells and that maintaining levels of IL-10 an anti-inflammatory cytokine may be beneficial for applications in wound healing.

Hydrogel systems have been recently used to deliver growth factors such as VEGF, keratinocyte growth factor, basic fibroblast fibroblast growth factor and hepatocyte growth factor for enhancing the wound healing process [33-35]. This delivery does not translate well in clinical settings, however, as is the case with becaplermin that consists of platelet-derived growth factor [36]; administering single growth factor to enhance angiogenesis in atherosclerotic patients has also shown little success [37]. During wound healing, multiple growth factors are known to work in synergistic fashion to provide a positive outcome [38]. The secretion of anti-apoptotic and angiogenic growth factors from stem cells can therefore provide a valuable tool for angiogenic therapies. In

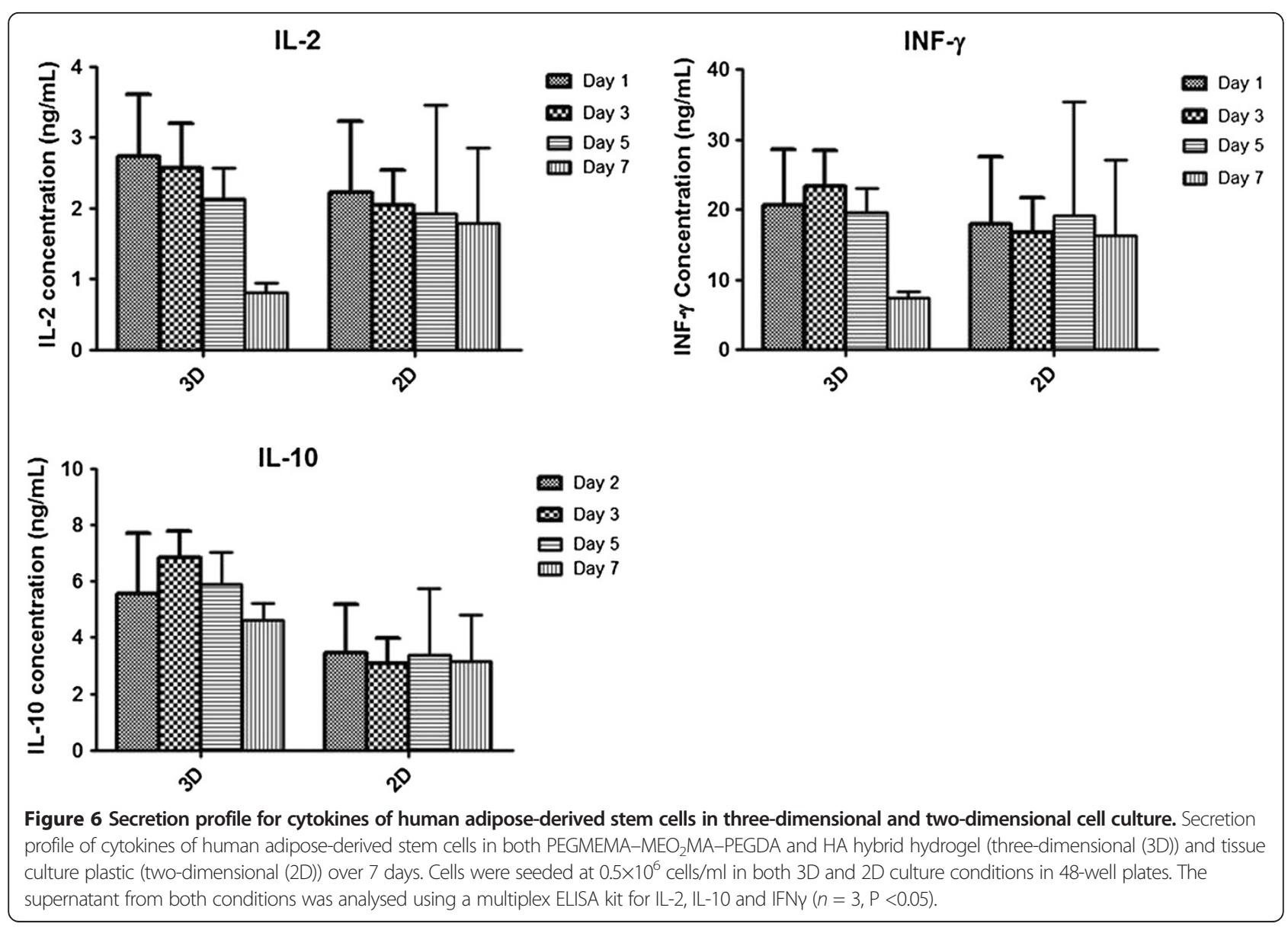


recent studies, hADSCs have been shown to enhance wound healing effectively by both directly differentiating or providing necessary growth factors and cytokines at local sites by enhancing angiogenic response [10]. These beneficial effects of hADSCs have been observed in ischemic models via promotion of angiogenesis by secretion of angiogenic cytokines such as VEGF and hepatocyte growth factor $[39,40]$. Therefore, after analysing the inflammatory cytokines, we decided to test for the secretion of pro-angiogenic growth factors.

For this purpose, we chose PlGF, VEGF and TGF- $\beta$. PIGF is a member of the VEGF family and both of these growth factors are potent angiogenic factors along with TGF- $\beta$, which is present in the initial stages of wound healing and regulates inflammatory cellular responses. hADSCs were seeded in P-SH-HA hydrogels at a density of $0.5 \times 10^{6}$ cells $/ \mathrm{ml}$. Supernatant was collected at days 1 , 3,5 and 7 after seeding. Cells plated on TCP were also used to analyse secretion. From the results it was noted that production of PlGF increased in both conditions (2D and 3D) over 7 days; however, there was significantly more PlGF present in the $3 \mathrm{D}$ culture system $(0 \mathrm{ng} / \mathrm{ml}$ at day 1 to $0.025 \pm 0.01 \mathrm{ng} / \mathrm{ml}$ at day 7) at 7 days when compared with day 1 (Figure 7 ). We also noted that VEGF production is lower in $3 \mathrm{D}$ culture than in $2 \mathrm{D}$ culture over all time points but the production of VEGF increased $(0.53 \pm 0.05 \mathrm{ng} / \mathrm{ml})$ over time from day 1 to day 7 (2.81 \pm $0.25 \mathrm{ng} / \mathrm{ml}$ ); a similar trend was noted in the media from TCP seeded cells (Figure 7). TGF- $\beta$ was also tested for release and showed increased production over time in both conditions (2D and 3D), but there was no significant difference in concentration levels at any time for 3D culture. These results suggest that hADSCs can secrete growth factors, albeit at low levels. PIGF interestingly increased over 7 days; however, the levels secreted were very low. It is important to note that chemical and mechanical properties of hydrogel can modulate the stem cell response; therefore it is necessary to test different conditions to optimise the production of pro-angiogenic growth factors. In conclusion, it can be observed that secretion and maintenance of pro-angiogenic and anti-inflammatory cytokines is possible in this P-SH-HA hydrogel system. The next step is therefore optimising this hydrogel system to increase the levels of secreted growth factors.

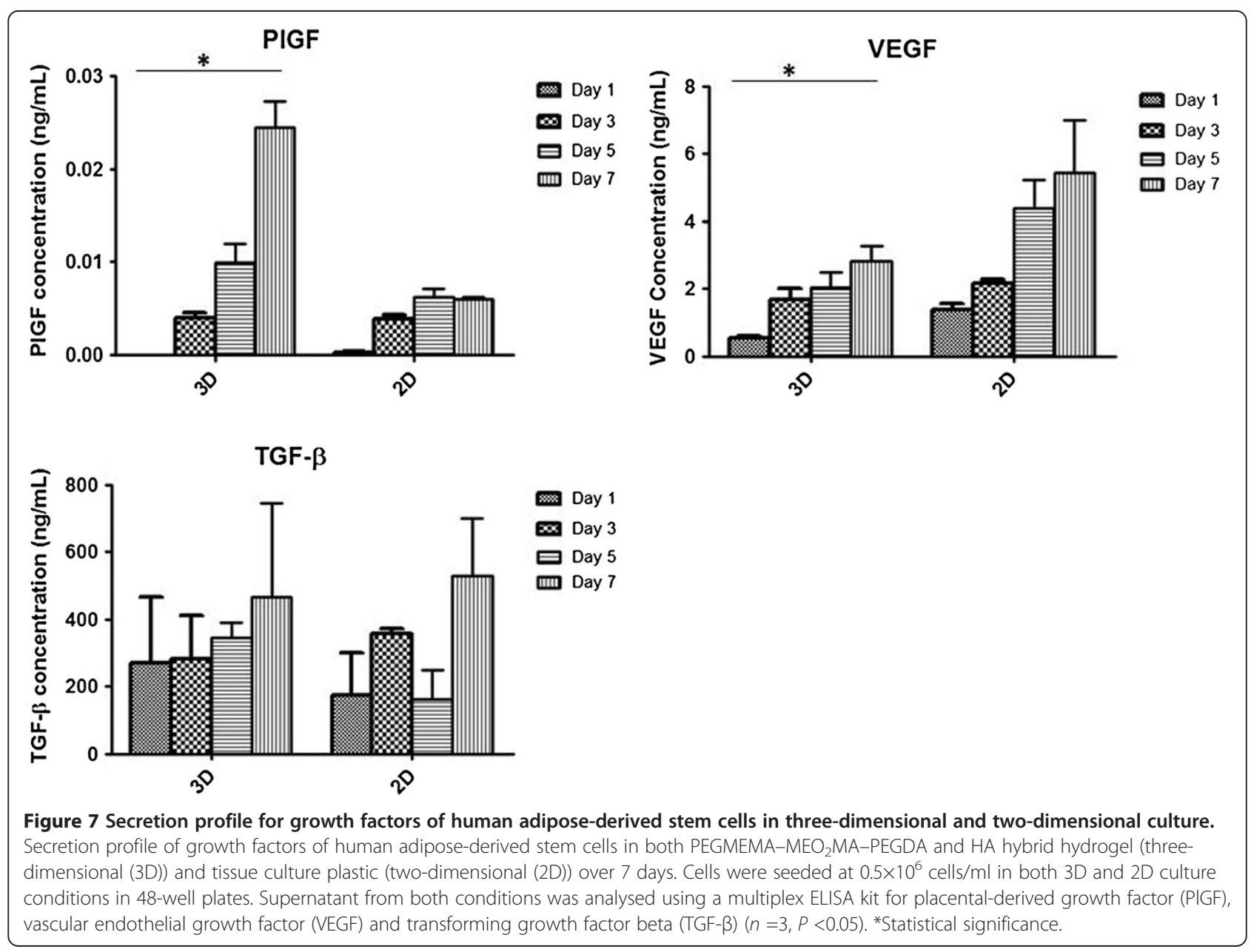




\section{Conclusion}

This study shows that hADSCs can be successfully encapsulated in a newly formed in situ P-SH-HA hydrogel system to support the maintenance of hADSCs and to secrete essential growth factors. P-SH-HA hydrogel does not induce cytotoxicity over a 7-day period as measured by cell viability with live/dead staining and the alamarBlue ${ }^{\circledR}$ assay. hADSCs successfully secreted proangiogenic growth factors (PIGF, VEGF and TGF- $\beta$ ) and did not induce toxicity or inflammatory response as evident by low production of proinflammatory cytokines (IFNY and IL-2). This in situ thermoresponsive copolymer with multiple acrylate groups has many advantages for the potential applications in tissue engineering and wound healing applications. The thermoresponsive property of this hydrogel allows easy handling during clinical practice and application as a dressing system. Furthermore, the multiple acrylate groups within the copolymer can provide tuneable mechanical properties leading to different swelling properties, to release profiles of growth factors from the gels and to allow control over secretion and cellular processes. Taken together, these results indicate that the PEG-HA-based synthetic extracellular matrix hydrogel can be used for topical application to deliver cells for wound healing applications.

\section{Abbreviations \\ 2D: Two-dimensional; 3D: Three-dimensional; ELISA: Enzyme-linked immunosorbent assay; HA: Hyaluronic acid; HA-SH: Thiol-modified hyaluronic acid; hADSC: Human adipose-derived stem cell; IFN: Interferon; IL: Interleukin; $\mathrm{MEO}_{2}$ MA: 2-(2-methoxyethoxy)ethyl methacrylate; NMR: Nuclear magnetic resonance; P-SH-HA: PEGMEMA-MEO 2 MA-PEGDA and HA hybrid; PBS: Phosphate-buffered saline; PEG: Polyethylene glycol; PEGDA: Poly (ethylene glycol) Diacrylate; PEGMEMA: Poly(ethylene glycol) methyl ether methylacrylate; PIGF: Placental-derived growth factor; RHAMM: Receptor for hyaluronan-mediated motility; TCP: Tissue culture plastic; TGF- $\beta$ : Transforming growth factor beta; VEGF: Vascular endothelial growth factor.}

\section{Competing interests}

The authors declare that they have no competing interests.

\section{Authors' contributions}

WW conceived the idea and designed the experiments, and WH and YD executed all of the experiments. WH, YD and WW interpreted and analysed the data and drafted the manuscript. WH was responsible for cell culture experiments, collection and assembly of data. YD contributed to the preparation of hydrogel materials. All authors read and approved the final manuscript.

\section{Acknowledgements}

The Heath Research Board of Ireland and the Science Foundation Ireland (SFI), the SFI Principal Investigator programme, DEBRA Ireland and DEBRA Austria, and the National University of Ireland, Galway are gratefully acknowledged for funding.

Received: 30 December 2012 Revised: 22 February 2013

Accepted: 14 March 2013 Published: 21 March 2013

\section{References}

1. Jones I, Currie L, Martin R: A guide to biological skin substitutes. Br J Plast Surg 2002, 55:185-193.

2. Cha J, Falanga V: Stem cells in cutaneous wound healing. Clin Dermatol 2007, 25:73-78.
3. Mimeault M, Hauke R, Batra SK: Stem cells: a revolution in therapeutics recent advances in stem cell biology and their therapeutic applications in regenerative medicine and cancer therapies. Clin Pharmacol Ther 2007, 82:252-264.

4. Lau K, Paus R, Tiede S, Day P, Bayat A: Exploring the role of stem cells in cutaneous wound healing. Exp Dermatol 2009, 18:921-933.

5. Falanga V, Schrayer D, Cha J, Butmarc J, Carson P, Roberts AB, Kim SJ: Full-thickness wounding of the mouse tail as a model for delayed wound healing: accelerated wound closure in Smad3 knock-out mice. Wound Repair Regen 2004, 12:320-326.

6. Guo SD, Dipietro LA: Factors affecting wound healing. J Dent Res 2010, 89:219-229

7. Werner S, Grose R: Regulation of wound healing by growth factors and cytokines. Physiol Rev 2003, 83:835-870.

8. Nauta AJ, Fibbe WE: Immunomodulatory properties of mesenchymal stromal cells. Blood 2007, 110:3499-3506.

9. Burdon TJ, Paul A, Noiseux N, Prakash S, Shum-Tim D: Bone marrow stem cell derived paracrine factors for regenerative medicine: current perspectives and therapeutic potential. Bone Marrow Res 2011, 2011:14. Article ID 207326.

10. Zuk PA, Zhu M, Mizuno H, Huang J, Futrell JW, Katz AJ, Benhaim P, Lorenz HP, Hedrick MH: Multilineage cells from human adipose tissue: implications for cell-based therapies. Tissue Eng 2001, 7:211-228.

11. Schäffler A, Büchler C: Concise review: adipose tissue-derived stromal cells-basic and clinical implications for novel cell-based therapies. Stem Cells 2007, 25:818-827.

12. Kim WS, Park BS, Sung JH: The wound-healing and antioxidant effects of adipose-derived stem cells. Expert Opin Biol Ther 2009, 9:879-887.

13. Ebrahimian TG, Pouzoulet $F$, Squiban $C$, Burad V, André M, Cousion B, Gourmelon P, Benderitter M, Casteilla L, Tamarat R: Cell therapy based on adipose tissue-derived stromal cells promote physiological and pathological wound healing. Arteriosclerosis, Thrombosis, and Vascular biology 2009, 29:503-510

14. Kim WS, Park BS, Sung JH, Yang JM, Park SB, Kwak SJ, Park JS: Wound healing effect of adipose-derived stem cells: a critical role of secretory factors on human dermal fibroblasts. J Dermatol Sci 2007, 48:15-24.

15. Wu KH, Mo XM, Han ZC, Zhaou B: Stem cell engraftment and survival in the ischemic heart. Ann Thorac Surg 2011, 92:1917-1925.

16. Lee K, Silva EA, Mooney DJ: Growth factor delivery-based tissue engineering: general approaches and a review of recent developments. J R Soc Interface 2011, 8:153-170.

17. Prestwich GD, Shu XZ, Liu Y, Cai S, Walsh JF, Hughes CW, Ahmad S, Kirker KR, Yu B, Orlandi RR, Park AH, Thibeault SL, Duflo S, Smith ME: Injectable synthetic extracellular matrices for tissue engineering and repair tissue engineering. Adv Exp Med Biol 2006, 585:125-133.

18. Slaughter BV, Khurshid SS, Fisher OZ, Khademhosseini A, Peppas NA: Hydrogels in regenerative medicine. Adv Mater 2009, 21:3307-3329.

19. Drury JL, Mooney DJ: Hydrogels for tissue engineering: scaffold design variables and applications. Biomaterials 2003, 24:4337-4351.

20. Brandl F, Sommer F, Goepferich A: Rational design of hydrogels for tissue engineering: impact of physical factors on cell behavior. Biomaterials 2007, 28:134-146.

21. Pang Y, Liu J, Wu J, Li G, Wang R, Su Y, He P, Zhu X, Yan D, Zhu B: Synthesis, characterization, and in vitro evaluation of long-chain hyperbranched poly(ethylene glycol) as drug carrier. Bioconjug Chem 2010, 21:2093-2102.

22. Lutolf MP, Hubbell JA: Synthetic biomaterials as instructive extracellular microenvironments for morphogenesis in tissue engineering. Nat Biotechnol 2005, 23:47-55.

23. Burdick JA, Vunjak-Novakovic G: Engineered microenvironments for controlled stem cell differentiation. Tissue Eng Part A 2009, 15:205-219.

24. Nicodemus GD, Bryant SJ: Cell encapsulation in biodegradable hydrogels for tissue engineering applications. Tissue Eng Part B Rev 2008, 14:149-165.

25. Gerecht S, Burdick JA, Ferreira LS, Townsend SA, Langer R, Vunjak-Novakovic $\mathrm{G}$ : Hyaluronic acid hydrogel for controlled self-renewal and differentiation of human embryonic stem cells. Proc Natl Acad Sci U S A 2007, 104:11298-11303.

26. Burdick JA, Prestwich GD: Hyaluronic acid hydrogels for biomedical applications. Adv Mater 2011, 23:H41-H56.

27. Dong Y, Hassan W, Zheng Y, Saeed AO, Cao H, Tai H, Pandit A, Wang W: Thermoresponsive hyperbranched copolymer with multi acrylate 
functionality for in situ cross-linkable hyaluronic acid composite semi-IPN hydrogel. J Mater Sci Mater Med 2012, 23:25-35.

28. Dong Y, Saeed AO, Hassan W, Keigher C, Zheng Y, Tai H, Pandit A, Wang W: 'One-step' Preparation of thiol-ene clickable PEG-based thermoresponsive hyperbranched copolymer for in situ crosslinking hybrid hydrogel. Macromol Rapid Commun 2012, 33:120-126.

29. Chicurel ME, Chen CS, Ingber DE: Cellular control lies in the balance of forces. Curr Opin Cell Biol 1998, 10:232-239.

30. Hachet E, Van Den Berghe H, Bayma E, Block MR, Auzély-Velty R: Design of biomimetic cell-interactive substrates using hyaluronic acid hydrogels with tunable mechanical properties. Biomacromolecules 2012, 13:1818-1827.

31. Lei Y, Gojgini S, Lam J, Segura T: The spreading, migration and proliferation of mouse mesenchymal stem cells cultured inside hyaluronic acid hydrogels. Biomaterials 2011, 32:39-47.

32. Chen X, Thibeault SL: Biocompatibility of a synthetic extracellular matrix on immortalized vocal fold fibroblasts in 3-D culture. Acta Biomater 2010, 6:2940-2948.

33. Lao G, Yan L, Yang C, Zhang L, Zhang S, Zhou Y: Controlled release of epidermal growth factor from hydrogels accelerates wound healing in diabetic rats. J Am Podiatr Med Assoc 2012, 102:89-98.

34. Peattie RA, Rieke ER, Hewett EM, Fisher RJ, Shu XZ, Prestwich GD: Dual growth factor-induced angiogenesis in vivo using hyaluronan hydrogel implants. Biomaterials 2006, 27:1868-1875.

35. Liu Y, Cai S, Shu XZ, Shelby J, Prestwich GD: Release of basic fibroblast growth factor from a crosslinked glycosaminoglycan hydrogel promotes wound healing. Wound Repair Regen 2007, 15:245-251.

36. Alfano C, Angelisanti M, Calzoni C, Somma F, Chiummariello S: Treatment of ulcer and difficult wounds of the lower limbs: our experience. Ann Ital Chir 2012, 83:135-141.

37. Henry TD, Annex BH, McKendall GR, Azrin MA, Lopez JJ, Giordano FJ, Shah PK, Willerson JT, Benza RL, Berman DS, Gibson CM, Bajamonde A, Rundle AC, Fine J, Mc Cluskey ER, VIVA Investigators: The VIVA trial, vascular endothelial growth factor in ischemia for vascular angiogenesis. Circulation 2003, 107:1359-1365.

38. Van Belle E, Witzenbichler B, Chen D, Silver M, Chang L, Schwall R, Isner JM: Potentiated angiogenic effect of scatter factor/hepatocyte growth factor via induction of vascular endothelial growth factor: the case for paracrine amplification of angiogenesis. Circulation 1998, 97:381-390.

39. Miranville $A$, Heeschen $C$, Sengenès $C$, Curat $C A$, Busse R, Bouloumié $A$ Improvement of postnatal neovascularization by human adipose tissuederived stem cells. Circulation 2004, 110:349-355.

40. Rehman J, Traktuev D, Li J, Merfeld-Clauss S, Temm-Grove CJ, Bovenkerk JE, Pell $\mathrm{CL}$, Johnstone BH, Considine RV, March KL: Secretion of angiogenic and antiapoptotic factors by human adipose stromal cells. Circulation 2004, 109:1292-1298.

doi:10.1186/scrt182

Cite this article as: Hassan et al:: Encapsulation and 3D culture of human adipose-derived stem cells in an in-situ crosslinked hybrid hydrogel composed of PEG-based hyperbranched copolymer and hyaluronic acid. Stem Cell Research \& Therapy 2013 4:32.

\section{Submit your next manuscript to BioMed Central and take full advantage of:}

- Convenient online submission

- Thorough peer review

- No space constraints or color figure charges

- Immediate publication on acceptance

- Inclusion in PubMed, CAS, Scopus and Google Scholar

- Research which is freely available for redistribution

Submit your manuscript at www.biomedcentral.com/submit
C Biomed Central 